\title{
The combination of Paclitaxel and Gefitinib inhibits endometrial cancer cells by inducing mitotic catastrophe: proof of principle for dual therapy in endometrial cancer
}

\author{
Xiangbing Meng ${ }^{1}$, Laura L. Laidler ${ }^{2}$, Lina Albitar ${ }^{2}$, Anna M. Holmes ${ }^{2}$, Donghai Dai ${ }^{1}$, \\ Thomas E. Buekers ${ }^{1}$, David P. Bender ${ }^{1}$, Kimberly K. Leslie ${ }^{1}$
}

Key Words: Paclitaxel, Gefitinib, endometrial cancer, mitotic catastrophe, p38, p53

Serous uterine endometrial cancer is a lethal disease for which new therapeutic regimens are urgently needed. Combinations of chemotherapeutic agents and small molecule growth factor inhibitors have demonstrated activity in cancers from other sites. Our objective was to determine whether such a combination could be active in serous endometrial cancer cells. The effects of the EGFR inhibitor gefitinib (ZD1839, Iressa) alone, paclitaxel alone, and the combination of both agents on the cell cycle and on cell proliferation were studied using Hec50co cells, a validated model for type II serous endometrial cancer with absent p53. First, we established the $\mathrm{IC}_{50}$ for paclitaxel alone (14 $\mathrm{nM}$ ) compared to that of paclitaxel and gefitinib in combination (1.3 nM). This 10 -fold reduction in the $\mathrm{IC}_{50}$ with dual therapy yielded a combination index of 0.25 , strongly suggesting that the paclitaxel and gefitinib combination resulted in synergistic growth inhibition. Sixty-seven percent of the cells treated with paclitaxel and gefitinib arrested in the $G_{2} / M$ phase. This arrest of the cell cycle at $G_{2} / M$ with combination therapy was significantly greater than with single agent treatment alone $(p<0.001)$ and was associated with inhibition of p38 phosphorylation and the induction of CDC25C phosphatase and Cyclin B1. When induced, these factors abrogate the G2/M checkpoint and result in rapid, premature progression to $\mathrm{M}$ phase; this mechanism is particularly active in the setting of absent p53. With rapid progression into $\mathrm{M}$, the cells were highly sensitive to paclitaxel and were killed by the mechanism of mitotic catastrophe. Similar findings were observed in the same cells treated with the combination

${ }^{1}$ Department of Obstetrics and Gynecology, UIHC, The University of lowa, lowa City, lowa 52242, ${ }^{2}$ University of New Mexico, Albuquerque, NM

Corresponding author: Xiangbing Meng, Department of Obstetrics and Gynecology, University of lowa, 3234 MERF, 200 Hawkins Drive, lowa City, IA, 52242. Telephone( 319) 335-8212 xiangbing-meng@uiowa.edu

This is an Open Access article distributed under the terms of the Creative Commons Attribution 3.0 Unported License (http://creativecommons.org/licenses/by/3.0), which permits unrestricted use, distribution, and reproduction in any medium, provided the original work is properly cited. 
AACR 101st Annual Meeting 2010, April 17-20,

Washington, DC

of paclitaxel and a specific inhibitor of p38, SB203580. Our study suggests that inhibition of EGFR or downstream p38 pathway can abrogate the mitotic stress checkpoint induced by cytotoxic

agents targeting microtubules such as paclitaxel. These findings suggest a new therapeutic strategy for the treatment of serous endometrial carcinoma worthy of clinical confirmation.

Paclitaxel and Gefitinib in endometrial cancer 